\title{
Range of echocardiographic findings in term neonates with high oxygen requirements
}

\author{
Nick Evans, Martin Kluckow, Andrew Currie
}

\begin{abstract}
Aims-To examine the hypothesis that right to left shunting occurs mainly in the lungs rather than through the fetal channels in neonates.

Methods-Thirty two term babies requiring over $70 \%$ oxygen had daily colour Doppler echocardiograms until recovery. Measurements included left ventricular fractional shortening, right and left ventricular outputs, colour and pulsed Doppler ductal and atrial shunting and systolic pulmonary artery pressure (SPAP) derived from ductal shunt or tricuspid incompetence velocities.
\end{abstract}

Results-The babies were retrospectively classified into a respiratory group $(n=19)$ and a persistent pulmonary hypertension (PPHN) group $(n=13)$ on the basis of clinical history and radiology. At the initial echocardiogram, just $50 \%$ of babies had suprasystemic SPAP. Despite better oxygenation, more of the PPHN group had suprasystemic PAP $(85 \%$ vs $26 \%)$. A correlation between SPAP and Oxygen index (OI) was present only in the respiratory group $(r=0.7)$. Low ventricular outputs $(<150 \mathrm{ml} / \mathrm{kg} / \mathrm{min}$ ) were common in both groups (53\% and $79 \%$ ). The respiratory group had more closed ducts $(47 \%$ vs $0 \%$ and those ducts which were patent were more constricted $(1.75 \mathrm{~mm}$ vs 2.6 $\mathrm{mm})$. Pure right to left ductal shunts were seen in just $15 \%$ and pure right to left atrial shunts in just $6 \%$ of all babies. The serial echocardiograms showed that SPAP fell and ducts closed well before oxygenation improved. Ventricular outputs increased with age in both groups.

Conclusions-Apart from early on in the sickest babies with a primarily respiratory diagnosis and the babies with primary PPHN, most right to left shunting occurred at an intrapulmonary level.

(Arch Dis Child Fetal Neonatal Ed 1998;78:F105-F111)

Keywords: pulmonary hypertension; echocardiography; right to left shunt

Department of

Royal Prince Alfred

Hospital and

University of Sydney,

Missenden Rd,

Camperdown, Sydney,

NSW 2050, Australia

$\mathrm{N}$ Evans

M Kluckow

A Currie

Correspondence to:

Dr Nick Evans.

Email:

nevans@med.usyd.edu.au nary shunting can be assessed, and ventricular outputs measured. Published reports of echocardiographic findings in babies with suspected persistent pulmonary hypertension (PPHN) have often focused on the early postnatal period ${ }^{2}$ or have studied selected groups of the very sickest babies. ${ }^{34}$ Our experience of echocardiographic assessment of unselected term babies with high oxygen requirements was that major degrees of right to left shunt at either atrial or ductal level were much less common than is often supposed. Firstly, because pulmonary artery pressures, although high, were often subsystemic and secondly, because the fetal channels, particularly the ductus arteriosus, tend to close early in the course of the disease. This caused us to question the extent to which extrapulmonary right to left shunting is the dominant cause of hypoxia in these babies.

This study aimed to document, in a serial manner, the range of echocardiographic findings in term and near term babies admitted to our intensive care unit with high oxygen requirements. Our hypotheses in doing this were firstly that many such babies do not have suprasystemic pulmonary artery pressures and secondly that right to left shunting through extrapulmonary fetal channels, particularly the ductus arteriosus, is not the dominant cause of hypoxia.

\section{Methods}

Babies included in this study were born after 35 weeks of gestation and had hypoxic respiratory failure requiring a fractional inspired oxygen concentration $\left(\mathrm{FIO}_{2}\right)$ of more than 0.7 to maintain adequate oxygenation. Thirty two eligible infants were studied between March 1993 and October 1995. The only eligible infants not studied were born when none of the investigators was available to perform an echocardiogram. The 32 infants studied had a median gestation of 39 weeks (range 36-42) and a median birthweight of $3392 \mathrm{~g}$ (range 1490$5720 \mathrm{~g}$ ). All the babies survived the neonatal period.

Echocardiograms were taken using an Acuson $128 / \mathrm{XP} 10$ ultrasound scanner with a 5 $\mathrm{MHz}$ or a $7 \mathrm{MHz}$ transducer, incorporating colour flow, pulsed wave, and continuous wave Doppler. The scan was recorded on to videotape and the measurements then taken from the videotape. Structural normality of the heart was established on the initial scan and infants with major congenital heart disease were excluded.

The timing of the initial scan was determined by the clinical presentation of the baby. Mean age at which the initial scan was taken 
was 23 hours, but ranged from 3 to 69 hours; just two babies had their initial scan after 48 hours due to late transfer from a level 2 hospital. Where possible, further scans were performed daily until the oxygen requirements had fallen. In most babies a final scan was performed once the baby had recovered and was breathing spontaneously in an $\mathrm{FIO}_{2}<0.3$.

\section{VENTRICULAR OUTPUTS}

Left ventricular function

Left ventricular fractional shortening was measured using a standardised method from $\mathrm{M}$-mode echocardiograms taken from the parasternal long axis view. ${ }^{5}$

\section{Right ventricular output ${ }^{6}$}

Pulsed Doppler recordings of the flow at the level of the pulmonary valve were made from the parasternal long axis view, care being taken to minimise the angle of insonation. An average maximum velocity time integral was derived from the area under the curve of five consecutive cardiac cycles, using the incorporated Acuson cardiac software. The heart rate was measured from the peak to peak intervals of the Doppler velocity time signals. The diameter of the pulmonary valve insertion was measured at end systole from a frame by frame videotape analysis of the $2 \mathrm{D}$ parasternal long axis image and was averaged from three to five cardiac cycles.

\section{Left ventricular output}

The left ventricular outflow tract was imaged from an apical view modified to incorporate the full length of the ascending aorta. ${ }^{7}$ The pulsed Doppler range gate was placed distal to the aortic valve and the angle correction incorporated into the Acuson 128/XP10 was aligned along the long axis of the ascending aorta. If the angle was more than $20^{\circ}$ the transducer was manoeuvred to minimise further the angle. The flow velocity time signal was recorded and the maximum velocity time integral averaged from five consecutive cardiac cycles. The heart rate was measured from the peak to peak intervals of the Doppler velocity time signals. The internal diameter of the ascending aorta at the site of flow analysis was measured at the end of systole using frame by frame analysis of the $2 \mathrm{D}$ image taken from a parasternal long axis view. This was averaged from three to five cardiac cycles.

The following formula was used to calculate ventricular outputs:

Right and left ventricular output index

$(\mathrm{ml} / \mathrm{kg} / \mathrm{min})=($ velocity time integral $\times$

$\left(\pi \times\right.$ [outflow diameter $\left.\left.{ }^{2} / 4\right]\right) \times$ heart rate $) /$ body weight

PULMONARY ARTERY PRESSURE AND DUCTUS ARTERIOSUS SHUNTING

Pulmonary artery pressure was assessed using three methods: pulmonary artery Doppler acceleration time; ductal shunt velocities; and tricuspid incompetence (TI) velocities. Because TI measurement of systolic pulmonary artery pressure (SPAP) is accepted as the most accurate of these methods, ${ }^{8}$ this is the result referred to when it was measurable. Assessment of SPAP from ductal shunt velocities was used if there was no TI. If neither was present, no figure for SPAP was derived.

Pulmonary artery time to peak velocity to right ventricular ejection time (TPV:RVET) ratio

This was measured in the main pulmonary artery as an index of pulmonary artery pressure. This ratio is inversely related to pulmonary artery pressure and is normally above 0.34 . A standard measurement procedure was used and the ratio was averaged from three to five cardiac cycles. ${ }^{9}$

\section{Ductus arteriosus shunt}

The ductus arteriosus was imaged from the high left parasternal view. Colour Doppler was set for automatic preprocessing, lowest velocity variance setting, and filters set for maximum range for volume and velocity settings with medium degree of motion discrimination (Acuson 128/XP10 filter setting 3). The colour flow Doppler mapping scale was set to the maximum range of the automatic preprocessing, usually the maximum velocity was between 0.64 to $0.8 \mathrm{~m} / \mathrm{seconds}$. The gain was set to optimise the colour flow image within the course of the duct and eliminate any peripheral colour interference. When patent, the minimum diameter (the site of maximum constriction) of the colour flow jet within the course of the ductus was measured from a frame by frame analysis of the videotape. End systolic frames with the clearest discrete appearance to the shunt within the duct were used for measurement. ${ }^{10} \mathrm{~A}$ mean was taken from 3 to 5 of the best quality cardiac cycles.

The shunt was assessed with pulsed and or continuous wave Doppler with the sample volume in the ductus arteriosus. The shunt pattern was classified as left to right, bidirectional, or right to left. SPAP was calculated using the following protocol. When the shunt was pure left to right, the peak velocity was measured and the SPAP was derived from the formula SPAP = systolic systemic blood pressure (SSBP) $-4 \mathrm{~V}^{2}$. When bidirectional, the proportion of the cardiac cycle with right to left shunting was measured as the time of right to left shunting divided by the total length of the cardiac cycle. Musewe et al ${ }^{11}$ showed that when right to left shunting occurs for less than $30 \%$ of the cardiac cycle, the SPAP is close to, but below, SSBP, and when more than $30 \%$ of the cardiac cycle, SPAP is above SSBP. So when right to left shunting was less than $30 \%$, the left to right peak velocity was measured and SPAP was derived from SPAP $=$ SSBP $-4 V^{2}$. When more than $30 \%$, the peak right to left velocity was measured and SPAP was derived from $\mathrm{SPAP}=\mathrm{SSBP}+4 \mathrm{~V}^{2}$.

\section{Tricuspid incompetence (TI)}

This was searched for using colour Doppler from the lower left parasternal and subcostal window. When present, the TI jet was sampled using continuous wave Doppler with the angle correction aligned along the long axis of the jet. The average maximum velocity of the jet was 
derived from two to three pansystolic jets. SPAP was derived from the formula SPAP = $4 \mathrm{~V}^{2}+5$ (assumed right atrial pressure). ${ }^{12}{ }^{13}$

ATRIAL SHUNTING

The atrial septum was imaged from a subcostal four chamber view and colour flow Doppler mapping of any shunt across the septum was performed. The colour flow Doppler was set as described in the section on ductal shunting. The peak frequency of the colour scale was usually set at 0.23 or $0.31 \mathrm{~m} / \mathrm{second}$, but sometimes higher for high velocity shunts. The gain was increased until the colour flow picture across the atrial septum was optimised and there was no peripheral colour interference. The diameter of the colour flow jet across the septum was measured at the level of the atrial septum. Frame by frame analysis of the videotape was performed until the clearest image of the left to right component of the interatrial shunt was achieved. The diameter was averaged from three to five of the clearest cardiac cycles. ${ }^{14}$ The pulsed Doppler range gate was placed in the interatrial shunt at the level of the atrial septum with the angle correction adjusted along the long axis of the colour flow of the shunt. The velocity time signal of the interatrial flow was recorded. The pattern of flow was classified as left to right, bidirectional, or right to left. When left to right or bidirectional, the peak left to right velocity was measured. When bidirectional, the proportion of the cardiac cycle with right to left shunting was measured as the time of right to left shunting divided by the total length of the cardiac cycle as described by Hiraishi et al. ${ }^{15}$

RESPIRATORY DISEASE

For each infant on each of the echocardiographic study days, hourly measures of $\left(\mathrm{FIO}_{2}\right)$ and mean airway pressure (MAP) were recorded from the continuous display on the ventilator. MAP and $\mathrm{FIO}_{2}$ were recorded at the time of echocardiography. Oxygenation index (OI) $\left.\left(\mathrm{MAP} \times\left[\mathrm{FIO}_{2} \times 100\right]\right) / \mathrm{PaO}_{2}\right)$ and alveolar to arterial oxygen gradient $\left(\mathrm{AaDO}_{2}\right)$ ([713$\left.\mathrm{FIO}_{2} / 100-\mathrm{PaCO}_{2} / 0.8\right]-\mathrm{PaO}_{2}$ ) at the time of the scan were calculated from the arterial blood gas sample taken nearest the scan, or an average of two samples if the scan was roughly halfway between two samples.

Systolic, diastolic, and mean blood pressures were recorded hourly from intra-arterial catheters. All parameters of blood pressure were also recorded at the time the scan was done.

Chest $x$-ray pictures were reported by a paediatric radiologist who was blinded to any clinical information about the baby.

Twenty $(63 \%)$ of the babies received inotropes, nine had dobutamine, four had dopamine, six had both dopamine and dobutamine and one baby had adrenaline. Ten babies had vasodilators, four had tolazoline (one with prostacyclin and one with nitric oxide), five babies had prostacyclin (one with nitric oxide) and one baby had just nitric oxide. Nitric oxide only became available for clinical use on our unit at the end of the study period. None of the babies was receiving vasodilators at the time of the initial echocardiogram. This study aimed to look at overall changes in haemodynamics and did not study in detail short term haemodynamic responses to vasodilators.

The study was approved by the Royal Prince Alfred Hospital ethics committee and infants were studied with the consent of their parents unless their was a clinical indication for an echocardiogram.

Statistical analysis was done using a computer statistics package (SPSSPC, SPSS inc, Chicago, Illinois) with stepwise multilinear regression analysis, Mann Whitney $U$ test, and $\chi^{2}$ test. $P$ values of less than 0.05 were accepted as significant.

\section{Results}

Term babies with high oxygen requirements represent a heterogenous clinical group. As the study progressed, it became apparent that haemodynamic patterns were emerging which related to whether there was radiological evidence of primary parenchymal lung disease. Therefore, for data analysis the infants were retrospectively divided into two groups on this basis, using the clinical history and chest $x$-ray reports generated by a paediatric radiologist blinded to the clinical history.

Thirteen of the $32(40 \%)$ babies had no clinical features of meconium aspiration or pneumonia and a normal or minimally abnormal chest $x$-ray appearance. These are referred to as the persistent pulmonary hypertension (PPHN) group. Eight of these babies had no obvious precipitant, one had a chromosome 4 deletion, one was the infant of a poorly controlled diabetic, and three had perinatal asphyxia in two of whom there was severe fetal anaemia.

In 19 of the 32 babies (60\%), on the basis of an appropriate clinical history (such as meconium aspirated from below the cords at birth) and abnormal opacification of the lung fields on chest $x$-ray, the primary pathology seemed to be in the pulmonary interstitium or airway. These are referred to as the respiratory group. Ten of these babies had meconium aspiration syndrome, one had post-asphyxia lung injury, two had hyaline membrane disease and six had non-specific respiratory disease. This latter diagnosis was made in babies who had clinically significant $x$-ray opacification but no evidence to support a diagnosis of meconium aspiration or infection.

The demographics and maximum respiratory support settings of these two groups are compared in table 1 . There were no differences in gestation, birthweight, or five minute Apgar scores. Both groups had similar maximum $\mathrm{FIO}_{2}$ and $\mathrm{AaDO}_{2}$, but the maximum $\mathrm{OI}$ and MAP were significantly higher in the respiratory group.

The clinical condition of the two groups of babies at the time of the initial scan are compared in table 2. The PPHN group were scanned significantly earlier and had significantly lower $\mathrm{FIO}_{2}, \mathrm{MAP}, \mathrm{OI}$ and $\mathrm{AaDO}_{2}$ at the time of the initial scan. Median systolic blood 
Table 1 Compares demographic and highest ventilatory settings in the respiratory and PPHN group of babies. Figures are medians (range)

\begin{tabular}{|c|c|c|c|c|}
\hline \multirow[b]{2}{*}{ Gestation (weeks) } & \multicolumn{2}{|c|}{ Respiratory group $(n=19)$} & \multicolumn{2}{|c|}{ PPHN group $(n=13)$} \\
\hline & 39 & $(36-42)$ & 40 & $(36-42)$ \\
\hline Birth Weight & 3285 & $(2410-5720)$ & 3550 & $(1490-4530)$ \\
\hline 5 minute Apgar & 8 & $(6-10)$ & 7 & $(3-10)$ \\
\hline Maximum $\mathrm{FIO}_{2}$ & 1.0 & $(0.92-1.0)$ & 1.0 & $(0.7-1.0)$ \\
\hline Maximum MAP & $15^{\star}$ & $(9-22)$ & $12^{\star}$ & $(0-16)$ \\
\hline Maximum oxygenation index & $25^{\star}$ & $(11-166)$ & $13^{\star}$ & $(0-47)$ \\
\hline Maximum $\mathrm{AaDO}_{2}$ & 615 & $(497-640)$ & 608 & $(365-655)$ \\
\hline
\end{tabular}

${ }^{\star} \mathrm{p}<0.05$.

Table 2 Compares clinical condition and echocardiographic findings at the initial echocardiogram. Figures are medians (range) or numbers (per cent)

\begin{tabular}{|c|c|c|c|c|c|}
\hline \multirow[b]{2}{*}{ Postnatal age (h) } & \multicolumn{2}{|c|}{$\begin{array}{l}\text { Respiratory group } \\
(n=19)\end{array}$} & \multicolumn{2}{|c|}{$P P H N$ group $(n=13)$} & \multirow{2}{*}{$\frac{p \text { Value }}{0.04}$} \\
\hline & 25 & $(4-69)$ & 9 & $(3-41)$ & \\
\hline $\mathrm{FIO}_{2}$ & 1.0 & $(0.9-1.0)$ & 0.97 & $(0.7-1.0)$ & 0.02 \\
\hline Oxygenation index & 20 & $(3.7-129)$ & 4.8 & $(0-14)$ & 0.0008 \\
\hline $\mathrm{AaDO}_{2}$ & 601 & $(391-626)$ & 522 & $(286-608)$ & 0.01 \\
\hline Systolic blood pressure & 57 & $(38-75)$ & 60 & $(41-78)$ & 0.7 \\
\hline \multicolumn{6}{|l|}{ Pulmonary artery pressure } \\
\hline TPV:RVET & 0.3 & $(0.18-0.39)$ & 0.21 & $(0.16-0.45)$ & 0.07 \\
\hline $\mathrm{SPAP}(\mathrm{mm} \mathrm{Hg})$ & 52 & $(39-70)$ & 67 & $(35-101)$ & 0.05 \\
\hline SPAP/SSBP & 0.92 & $(0.63-1.75)$ & 1.229 & $(0.65-1.7)$ & 0.06 \\
\hline SPAP $>$ SSBP & $26 \%$ & & $85 \%$ & & 0.001 \\
\hline \multicolumn{6}{|l|}{ Ductal shunting } \\
\hline Ductus closed & 9 & $(47 \%)$ & 0 & $(0 \%)$ & 0.003 \\
\hline Left to right shunt & 4 & $(21 \%)$ & 1 & $(8 \%)$ & \\
\hline Bidirectional shunt & 3 & $(16 \%)$ & 10 & $(77 \%)$ & \\
\hline Right to left shunt & 3 & $(16 \%)$ & 2 & $(15 \%)$ & \\
\hline $\mathrm{R}-\mathrm{L}$ shunt/cardiac cycle & $41 \%$ & $(18-100)$ & $36 \%$ & $(22-100)$ & \\
\hline Diameter of PDAs (mm) & 1.75 & $(1.2-4.7)$ & 2.6 & $(1.5-5.3)$ & 0.0014 \\
\hline \multicolumn{6}{|l|}{ Ventricular function and outputs } \\
\hline LV fractional shortening & 31 & $(1-55)$ & 27 & $(12-45)$ & 0.8 \\
\hline $\mathrm{RV}$ output $\mathrm{ml} / \mathrm{kg} / \mathrm{min}$ & 138 & $(56-354)$ & 193 & $(85-255)$ & 0.16 \\
\hline $\mathrm{LV}$ output $\mathrm{ml} / \mathrm{kg} / \mathrm{min}$ & 138 & $(93-240)$ & 149 & $(66-234)$ & 0.77 \\
\hline RV or LV output $<150$ & $79 \%$ & & $53 \%$ & & 0.13 \\
\hline \multicolumn{6}{|l|}{ Atrial shunting } \\
\hline No shunt & 2 & $(10 \%)$ & 2 & $(15 \%)$ & \\
\hline Left to right shunt & 4 & $(20 \%)$ & 2 & $(15 \%)$ & \\
\hline Bidirectional shunt & 11 & $(60 \%)$ & 9 & $(70 \%)$ & \\
\hline Right to left shunt & 2 & $(10 \%)$ & 0 & $(0 \%)$ & \\
\hline R-L shunt/cardiac cycle & $48 \%$ & $(18-100)$ & $36 \%$ & $(13-61)$ & \\
\hline Atrial shunt diameter (mm) & 3.35 & $(1.5-6.5)$ & 3.9 & $(1.1-5.3)$ & 0.78 \\
\hline
\end{tabular}

pressure was not significantly different. The scan findings in both groups are compared in table 2 .

Among the babies in whom it was measurable $(63 \%$ of the respiratory babies and all the PPHN babies), SPAP was significantly higher in the PPHN group despite having lower ventilatory settings $(p=0.05)$. Significantly more of the PPHN group had suprasystemic SPAP, $85 \%$ compared with just $26 \%$ of the respiratory group $(\mathrm{p}=0.001)$. The seven babies in the respiratory group without a measurable SPAP had no evidence of suprasystemic pressures on $2 \mathrm{D}$ imaging and their median TPV:RVET was $0.34(0.23-0.38)$, just below the normal range. Multilinear regression analysis was performed to look for significant clinical associations with the ratio of SPAP to SSBP (a ratio greater than 1 showing suprasystemic SPAP). Independent clinical and echocardiographic parameters examined included: postnatal age, left ventricular fractional shortening, heart rate, left and right ventricular output, ductal and atrial shunt diameter, SSBP, and respiratory support at the time of the scan including $\mathrm{FIO}_{2}, \mathrm{MAP}$, OI and $\mathrm{AaDO}_{2}$. When all 32 babies studied where included, there were no significant associations with SPAP:SSBP. Likewise no associations were found when the analysis was confined to the PPHN group. However, when the same multivariant analysis was confined to the respiratory babies, there was a significant relation between SPAP:SSBP and OI (cumulative $r=0.7, p=0.02$ ) (fig 1 ). With one exception, the SPAP was suprasystemic only when the OI was over 35 .

Only $53 \%$ of the respiratory group had a patent ductus arteriosus (PDA) and most of these showed constriction, with a median diameter of $1.75 \mathrm{~mm}$. All the babies in the PPHN group had a PDA, again many were constricted but the median diameter at $2.6 \mathrm{~mm}$ was significantly larger than the PDAs in the respiratory group; $\mathrm{p}=0.0014$ (an unconstricted PDA in a term baby is 3 to $5 \mathrm{~mm}$ in diameter). ${ }^{2}$ In four $(21 \%)$ of the respiratory group and one $(8 \%)$ of the PPHN group, the shunt was pure left to right. In the others, the shunt was bidirectional or, in two (16\%) PPHN babies and three $(16 \%)$ respiratory, pure right to left. Where it was present, right to left shunting occupied a median $36 \%$ of the cardiac cycle in the respiratory group and $41 \%$ in the PPHN group.

Overall median left ventricular fractional shortening was $29 \%$ (range 0-53). Just six babies $(18 \%)$ had left ventricular fractional shortening below $20 \%$, the lower limit of the normal newborn range. ${ }^{4}$ However, ventricular outputs were low in both groups. Seventy nine per cent of the respiratory group and $53 \%$ of the PPHN group had a right or left ventricular output less than $150 \mathrm{ml} / \mathrm{kg} / \mathrm{min}$ (normal range $200-300 \mathrm{ml} / \mathrm{kg} / \mathrm{min}^{16}{ }^{17}$ ). Twenty per cent of all the babies had one ventricular output below $100 \mathrm{ml} / \mathrm{kg} / \mathrm{min}$. Right ventricular output was higher than left ventricular output in the PPHN group, reflecting right to left ductal shunting (table 2).

Most babies had some atrial shunting and the colour Doppler diameter of those shunts was similiar in both groups. Just two babies in each group had no detectable interatrial shunt. In the respiratory group, four $(20 \%)$ had pure left to right shunt, $11(60 \%)$ had a bidirectional shunt, and just two (10\%) had a pure right to left shunt. In the PPHN group, two (15\%) had pure left to right shunt, nine $(70 \%)$ had a bidirectional shunt, with none having a pure right to left shunt. In those with bidirectional or pure right to left shunts, right to left shunting occupied a median $48 \%$ of the cardac cycle in the respiratory group and $36 \%$ in the PPHN group. Right to left atrial shunting for up to

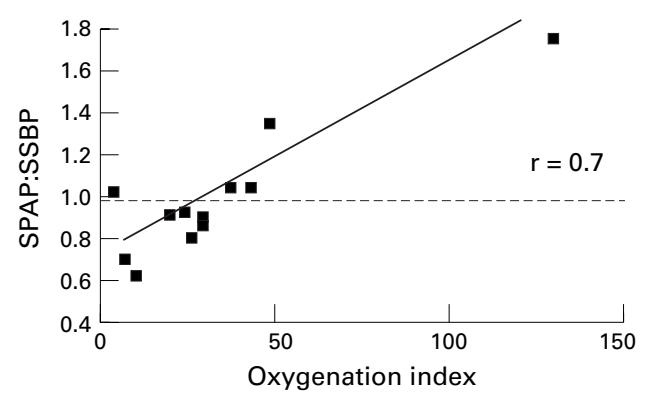

Figure 1 Correlation between the ratio of systolic pulmonary pressure (SPAP) to systolic systemic pressure $(S S B P)$ and the OI in babies with a primary respiratory diagnosis; $r=0.7 ; p=0.001$. 
Table 3 Serial acute echocardiographic findings in the respiratory group. Figures are medians (range) or numbers (per cent)

\begin{tabular}{|c|c|c|c|c|}
\hline & Day $1 / 2(n=19)$ & Day $3(n=12)$ & Day $4(n=13)$ & Day 5 or $6(n=11)$ \\
\hline Age $(\mathrm{h})$ & $25 \quad(4-69)$ & $(46-72)$ & $(72-96)$ & $104 \quad(96-144)$ \\
\hline $\mathrm{FIO}_{2}$ & $1.0(0.9-1.0)$ & $1.0(0.45-1.0)$ & $0.85(0.45-1.0)$ & $0.7(0.34-1.0)$ \\
\hline SPAP $>$ SSBP & $26 \%$ & $8 \%$ & $0 \%$ & $0 \%$ \\
\hline LVO or RVO $<150$ & $79 \%$ & $33 \%$ & $23 \%$ & $18 \%$ \\
\hline Ductus closed & $9 / 19 \quad(48 \%)$ & $10 / 12 \quad(83 \%)$ & $(92 \%)$ & $11 / 11 \quad(100 \%)$ \\
\hline
\end{tabular}

LVO or RVO is left or right ventricular output.

Table 4 Serial acute echocardiographic findings in the PPHN group. Figures are medians (range) or numbers (per cent)

\begin{tabular}{|c|c|c|c|c|}
\hline & Day $1 / 2(n=12)$ & Day $3(n=10)$ & Day $4(n=10)$ & Day 5/6 $(n=6)$ \\
\hline Age (h) & $(3-41)$ & $(50-70)$ & $(72-94)$ & $(96-130)$ \\
\hline $\mathrm{FIO}_{2}$ & $0.97(0.65-1.0)$ & $0.93(0.35-1.0)$ & $0.87(0.4-1.0)$ & $0.75(0.35-1.0)$ \\
\hline SPAP $>$ SSBP & $85 \%$ & $50 \%$ & $10 \%$ & $33 \%$ \\
\hline LVO or RVO $<150$ & $53 \%$ & $60 \%$ & $30 \%$ & $50 \%$ \\
\hline Ductus closed & $0 / 12$ & $(50 \%)$ & $(80 \%)$ & $(66 \%)$ \\
\hline
\end{tabular}

LVO or RVO is left or right ventricular output.

Table 5 Compares clinical condition and echocardiographic findings when the two groups of babies were off the ventilator and in less than $30 \%$ oxygen. Figures are median (range) or numbers (per cent)

\begin{tabular}{|c|c|c|c|c|c|}
\hline \multirow[b]{2}{*}{ Postnatal age $(\mathrm{h})$} & \multicolumn{2}{|c|}{$\begin{array}{l}\text { Respiratory group } \\
(n=12)\end{array}$} & \multicolumn{2}{|c|}{$\begin{array}{l}\text { PPHN group } \\
(n=10)\end{array}$} & \multirow[t]{2}{*}{$p$ Value } \\
\hline & 146 & $(79-329)$ & 210 & $(58-602)$ & \\
\hline $\mathrm{FIO}_{2}$ & 0.21 & $(0.21-0.3)$ & 0.21 & $(0.21-0.28$ & \\
\hline \multicolumn{6}{|l|}{ Pulmonary Artery Pressure } \\
\hline TPV:RVET & 0.36 & $5(0.26-0.44)$ & 0.37 & $7(0.23-0.45)$ & \\
\hline $\mathrm{SPAP}(\mathrm{mm} \mathrm{Hg})$ & 35 & $(25-37)(n=3)$ & 44 & $(25-66)(n=4)$ & \\
\hline \multicolumn{6}{|l|}{ Ductal shunting } \\
\hline Ductus closed & 12 & $(100 \%)$ & 7 & $(70 \%)$ & 0.003 \\
\hline Left to right shunt & N/A & & 2 & $(20 \%)$ & \\
\hline Bidirectional shunt & N/A & & 1 & $(10 \%)$ & \\
\hline Diameter of PDA's (mm) & $\mathrm{N} \backslash \mathrm{A}$ & & 1.5 & $(0.8-1.6)$ & \\
\hline \multicolumn{6}{|l|}{ Ventricular function and outputs } \\
\hline LV fractional shortening & 30 & $(21-40)$ & 25 & $(20-47)$ & 0.8 \\
\hline $\mathrm{RV}$ output $\mathrm{ml} / \mathrm{kg} / \mathrm{min}$ & 237 & $(176-342)$ & 193 & $(121-491)$ & 0.16 \\
\hline LV output $\mathrm{ml} / \mathrm{kg} / \mathrm{min}$ & 240 & $(178-403)$ & 194 & $(128-320)$ & 0.77 \\
\hline RV or LV output $<150$ & $0 \%$ & & $30 \%$ & & 0.13 \\
\hline \multicolumn{6}{|l|}{ Atrial shunting } \\
\hline No shunt & 5 & $(41 \%)$ & 5 & $(50 \%)$ & \\
\hline Left to right shunt & 3 & $(25 \%)$ & 3 & $(30 \%)$ & \\
\hline Bidirectional shunt & 4 & $(34 \%)$ & 2 & $(20 \%)$ & \\
\hline R-L shunt/cardiac cycle & 0.28 & $3(0.25-0.42)$ & 0.22 & $(0.25-0.42)$ & \\
\hline Atrial shunt diameter $(\mathrm{mm})$ & 3.35 & $(1.5-6.5)$ & 3.9 & $(1.1-5.3)$ & 0.78 \\
\hline
\end{tabular}

$30 \%$ of the cardiac cycle occurs in normal healthy newborns. ${ }^{15}$

Serial studies were performed in all babies except four in the respiratory group. Three of these babies were transferred out, one for ECMO, two for nitric oxide. None of the investigators was available to do serial studies on the other baby. Babies were included in this analysis if they still had an $\mathrm{FIO}_{2}$ requirement $>0.3$. Not all babies were scanned on every day; the numbers scanned on each day are shown in tables 3 and 4 .

Serial echocardiographic findings in the respiratory group are summarised in table 3 . Haemodynamics normalised in this group of babies despite median $\mathrm{FIO}_{2}$ remaining high. Definite evidence of suprasystemic SPAP was seen in just one baby on day 3, but no babies after that time. Cardiac outputs improved and by days 5 and 6 , over $80 \%$ of the babies had ventricular outputs over $150 \mathrm{ml} / \mathrm{kg} / \mathrm{min}$. In most babies the ductus arteriosus closed early, with just two babies on day 3 and one on day 4 having a PDA. No baby in this group had a PDA after this time. Of the four babies not studied serially, one had a closed duct on the inital scan and the other three had constricted ducts $(1.1 \mathrm{~mm}, 1.2 \mathrm{~mm}$, and $2 \mathrm{~mm}$ in diameter). There was no significant change in either the size or the direction pattern of atrial shunts during this time.

Serial echocardiographic findings in the PPHN group are summarised in table 4. All these babies were studied serially, but several recovered during the first six days, hence the smaller numbers studied on each day, as shown in table 4. Haemodynamics took longer to return to normal in some of these babies, with low ventricular outputs and suprasystemic SPAP and PDAs seen in a few of these babies up to day 6 (table 4). Most of the ducts, however, (10/13) were closed after day 3 and there was no significant change in either the size or the direction pattern of the atrial shunts during this time.

Recovery was defined as breathing spontaneously in a $\mathrm{FIO}_{2}<0.3$. The echocardiographic findings at this time for 12 babies in the respiratory group and 10 babies in the PPHN group are compared in table 5. Pulmonary artery pressure, as assessed by TPV:RVET, had returned to the normal range in most babies. However, one baby in the PPHN group had ductal shunt and TI evidence of high SPAP $(\mathrm{SPAP} / \mathrm{SSBP}=0.99)$ and yet remained stable in low inspired oxygen. Ventricular outputs also returned to normal in most babies, but again outputs below $150 \mathrm{ml} / \mathrm{kg} / \mathrm{min}$ were still present in three babies in the PPHN group. Three babies in the PPHN group also had shunting through a tightly constricted duct. About half the babies had no atrial shunt; of the others, half still showed a bidirectional pattern. None of the differences between the groups was significant.

\section{Discussion}

While previous studies have used echocardiography to examine early haemodynamics in term and near term babies with severe hypoxic respiratory failure, to our knowledge this is the first study to have looked at this serially through to recovery. The babies in this study will represent the type of babies that most neonatal intensive care units treat, in that they were either inborn or, if outborn, were transferred for routine intensive care not for specific rescue therapies. The distinction of PPHN into that which is primary and that which is secondary to lung disease has long been recognised but is seldom referred to. ${ }^{18}$ In this study we have shown widely varying echocardiographic findings and, having divided the babies into PPHN and respiratory groups on the basis of the radiological and clinical findings, have shown differences in presentation and serial haemodynamics.

These differences between the groups are emphasised by the factors which relate to the degree of pulmonary hypertension. Like Skinner et $a l,{ }^{4}$ we found no relation in the group as a whole between the degree of pulmonary hypertension and the severity of the hypoxic respiratory failure. However, when we analysed the subgroup of respiratory babies separately, there was a significant positive correlation. This is in keeping with the findings of Walther et $a l,^{2}$ who also showed a good correlation in 
babies who mainly had meconium aspiration. In contrast, the PPHN group of babies had no clinical factors relating to PAP. These babies had significantly higher PAPs than the respiratory group, despite being easier to oxygenate and ventilate. Different patterns were also seen in the serial studies. In the respiratory babies, haemodynamics quickly returned to normal with suprasystemic PAPs not seen after day 3 . But, while many of the PPHN babies improved quickly, some showed prolonged reactivity of the vasculature. One baby with radiologically clear lungs that were easy to ventilate, continued to return to very high PAPs for three weeks each time the ventilator was weaned.

High PAP has two important haemodynamic effects: hypoxic blood bypasses the lungs through the extrapulmonary fetal channels and ventricular outputs are restricted. The first is well recognised and while this does occur, particularly during the transitional circulation period, ${ }^{2}$ these data show it is not as common as is often assumed after the first 24 hours. This is firstly because PAPs are often subsystemic, but more importantly because the fetal channels, particularly the ductus arteriosus, constrict and close early in the clinical course. In the respiratory group significant right to left ductal shunting was confined to the very sickest babies, usually through a very constricted ductus. Initially, the PPHN babies did have larger PDAs with more right to left shunting, but despite this, these babies were significantly easier to oxygenate than the respiratory group of babies. In both groups the normal postnatal ductal constrictive mechanisms seemed to work well and most ducts were closed well before the oxygenation improved.

Fox and Duara ${ }^{19}$ recognised, using pre- and postductal $\mathrm{pO} 2$, that $50 \%$ of term babies with suspected PPHN had no evidence of right to left ductal shunting. It was argued that in such babies the shunt must be occurring at atrial level. However, in most babies we were also unable to show major degrees of right to left atrial shunt. It is important to recognise that a bidirectional atrial shunt pattern with right to left shunting for up to $30 \%$ of the cardiac cycle is normal in well newborns. ${ }^{15}$ At the initial assessment in those with some right to left shunting, the proportion was higher than this $-48 \%$ in respiratory babies and $36 \%$ in the PPHN babies - but in most babies most of the cardiac cycle was occupied by left to right shunt. The colour Doppler diameter of these shunts also varied widely; some were large but many were small and difficult to find on colour Doppler. There are no normative data in term babies, but in a group of preterm babies $(<1500 \mathrm{~g})$ we found atrial shunts had to be over $4 \mathrm{~mm}$ in diameter before shunts were consistently haemodynamically significant. ${ }^{14}$ Median shunt diameters in these term babies, were 3.3 $\mathrm{mm}$ and $3.9 \mathrm{~mm}$ in the respective groups. Pure right to left atrial shunts were seen in the very sickest babies in the respiratory group but not at all in the PPHN group. In general, atrial shunts were small in diameter and proportion of right to left shunt was only slightly greater than that which is seen in normal babies.
The restriction of ventricular outputs is a less well recognised consequence of high pulmonary vascular resistance. This problem affected both groups, with most of the babies having one ventricular output below the normal range at their initial scan. This has been shown before and has been related to death and requirement for ECMO. ${ }^{3}{ }^{4}$ These low outputs probably have several causes. Like Skinner et al, ${ }^{4}$ we found little evidence that left ventricular myocardial dysfunction was an important component in most babies, with only $18 \%$ having a left ventricular fractional shortening below the normal range. Right ventricular myocardial function is more difficult to quantify, but we observed qualitatively that several babies had significant right ventricular dysfunction, particularly when the PVR was very high and the ductus arteriosus was closing. In this situation, myocardial dysfunction is not the primary problem but is the consequence of extreme afterloads. This has a knock-on effect to the rest of the circulation: low pulmonary blood flow in turn lowers preload on the left ventricle and, because of the Starling effect, lower preload will reduce left ventricular myocardial function and outputs. High positive pressure ventilation also directly increases pulmonary vascular resistance, ${ }^{20}$ an effect which may partly explain the suprasystemic PAPs seen in the sickest of the respiratory babies. Thus we suggest that low cardiac outputs in most babies with PPHN are secondary to high circuit resistance and positive pressure ventilation, not primary pump failure. These low systemic flows may be just as important, in terms of tissue oxygen delivery, as low arterial oxygen levels and perhaps just as important to correct with therapeutic manoeuvres.

The results of this study question the common assumption that hypoxia in term babies with high oxygen requirements is due to blood bypassing the lungs through the extrapulmonary fetal channels. This does occur in those with the highest PAP, but in most, most of the cardiac output is passing through the lungs. So why do these babies become so hypoxic? Empirically, the major shunt must be occurring at an intrapulmonary level, and extrapulmonary right to left shunts, when they occur, compound this but are not the dominant cause of the hypoxia. This concept is supported by the variable nature of response of these babies to pulmonary vasodilators. Even in babies who improve their oxygenation and haemodynamics with a specific vasodilator such as nitric oxide, there is usually still a clinically significant residual oxygen requirement. ${ }^{1}$ The other paradox is the observation of babies with very high SPAP and right to left extrapulmonary shunts who have minimal oxygen requirements. This was documented in one baby in this study on the recovery scan and we have seen this phenomenon on several other occasions. This concept of intrapulmonary shunting leading to hypoxia is understandable with the ventilation-perfusion mismatch of severe lung disease, but is more difficult to conceptualise in the baby with relatively normal lungs after the duct has closed. Where 
is the shunt occuring? Further understanding of the hypoxic processes in PPHN may be achieved by studying what is happening at a microvascular level in the lungs. Possible explanations for intrapulmonary shunting and hypoxia might include shunting through vessels that interface poorly with the alveolar septum, such as alveolar corner vessels, ${ }^{21}$ high transpulmonary vascular pressure gradient shortening lung blood transit times to the point where there is insufficient time for complete gas exchange, ${ }^{22}$ or low mixed venous oxygen resulting from low systemic blood flows, as has been suggested in adult onset pulmonary hypertension. ${ }^{23}$

These data emphasise the need for more precise clinical definitions of PPHN along the lines suggested before. ${ }^{18}$ The term PPHN should be reserved for the babies with minimal radiological lung changes. It is to these babies that study of pulmonary vascular endothelial dysfunction is likely to be most relevant. ${ }^{24}$ While there is almost certainly some overlap, when the radiological changes point to disease in the pulmonary interstitium, pulmonary hypertension is likely to be secondary and haemodynamics are more likely to be determined by acid-base status, oxygenation, and ventilatory pressures than endothelial dysfunction.

There is also a need for more precise echocardiographic criteria for what constitutes significantly raised pulmonary artery pressure. In term babies with high oxygen requirements we have shown a wide range of pulmonary artery pressures, but in almost all the pulmonary artery pressure would be above normal. We suggest that the term pulmonary hypertension should be applied when pulmonary artery pressure is shown to be close to or above systemic blood pressure, and there are demonstrable haemodynamic consequences, either large right to left extrapulmonary shunts, or restricted cardiac output.

Previous echocardiographic studies have suggested that the variable responses to pulmonary vasodilator therapies, including nitric oxide, relate to the range of haemodynamics. ${ }^{25} 26$ We speculate that the underlying disease process may also be important in determining responses to therapies. More precise clinical and haemodynamic definitions of PPHN will facilitate our understanding of both the underlying disease process and the diversity of responses to treatment in these babies.

1 Kinsella JP, Abman SH. Recent developments in the pathophysiology and treatment of persistent pulmonary hypertension of the newborn. F Pediatr 1995;126:853-64.
2 Walther FJ, Benders MJ, Leighton JO. Early changes in the neonatal circulatory transition. F Pediatr 1993;123:625-32.

3 Kinsella JP, McCurnin DC, Clark RH, Lally KP, Null DM. Cardiac performance in ECMO candidates: echocardiographic predictors for ECMO. F Pediatr Surg 1992;27:447.

4 Skinner JR, Hunter S, Hey E. Haemodynamic features at presentation in persistent pulmonary hypertension of the newborn and outcome. Arch Dis Child 1996;74:F26-32.

5 Sahn DJ, DeMaria A, Kisslo J, Weyman A. Recommendations regarding quantitation in $M$-mode echocardiography: Results of a survey of echocardiographic measurements. Circulation 1978;58:1072-83.

6 Sholler GF, Celermajer JM, Whight CM, Bauman AE. Echo Doppler assessment of cardiac output and its relation to growth in normal infants. Am f Cardiol 1987;60:1112-6.

7 Mandelbaum Isken $\mathrm{VH}$, Linderkamp O. Cardiac output by pulsed Doppler in neonates using the apical window. Pediatr Cardiol 1991;12:13-6.

8 Chan KL, Currie PJ, Seward JB, Hagler DJ, Mair DD, Tajik AJ. Comparison of three Doppler ultrasound methods in the prediction of pulmonary artery pressure. $7 \mathrm{Am}$ Coll Cardiol 1987;9:549-54.

9 Evans NJ, Archer LN. Doppler assessment of pulmonary artery pressure and extrapulmonary shunting in the acute phase of hyaline membrane disease. Arch Dis Child 1991;66:6-11.

10 Evans N, Iyer P. Assessment of ductus arteriosus shunt in preterm infants supported by mechanical ventilation: effect of interatrial shunting. F Pediatr 1994;125:778-85.

11 Musewe NN, Poppe D, Smallhorn JF, et al. Doppler echocardiographic measurement of pulmonary artery pressure from ductal Doppler velocities in the newborn. $\mathcal{f}$ Am Coll Cardiol 1990;15:446-56.

12 Skinner JR, Stuart AG, O'Sullivan J, Heads A, Boys RJ, Hunter S. Right heart pressure determination by Doppler in infants with tricuspid regurgitation. Arch Dis Child 1993;69:216-20.

13 Skinner JR, Milligan DW, Hunter S, Hey EN. Central venous pressure in the ventilated neonate. Arch Dis Child 1992;67:374-7.

14 Evans N, Iyer P. Incompetence of the foramen ovale in preterm infants supported by mechanical ventilation. $\mathcal{F}$ Pediatr 1994;125:786-92

15 Hiraishi S, Agata Y, Saito K, et al. Interatrial shunt flow profiles in newborn infants: a colour flow and pulsed Doppler echocardiographic study. Br Heart F 1991; 65:41-5.

16 Agata Y, Hiraishi S, Oguchi K, et al. Changes in left ventricular output from fetal to early neonatal life. 7 Pediatr 1991;119:441-5.

17 Walther FJ, Siassi B, Ramadan NA, Ananda AK,Wu PY. Pulsed Doppler determinations of cardiac output in neonates: normal standards for clinical use. Pediatrics 1985;76:829-33.

18 Gersony W $M$. Persistence of the fetal circulation: A commentary. F Pediatr 1973;82:1103-6.

19 Fox WW, Duara S. Persistent pulmonary hypertension in the neonate: diagnosis and management. $f$ Pediatr 1983;103:505-14.

20 Dhainaut JF, Devaux JY, Monsallier JF, Brunet F, Villemant D, Huyghebaert MF. Mechanisms of decreased left ventricular preload during continuous positive pressure ventilation in ARDS. Chest 1986;90:74-80.

21 Conhaim RL, Harms BA. Perfusion of alveolar septa in isolated rat lungs in zone 1. F Appl Physiol 1993;75:704-11.

22 Hill E P, Power GG, Longo LD, West JB, eds. Kinetics of $\mathrm{O}_{2}$ and $\mathrm{CO}_{2}$ exchange. In: Bioengineering aspects of the lung. New York: Marcel Dekker, 1977: 459-514.

23 Manier G, Castaing Y. Contribution of multiple inert gas elimination technique to pulmonary medicine.4. Gas exchange abnormalities in pulmonary vascular and cardiac disease. Thorax 1994;49:1 169-74.

24 Ziegler JW, Ivy DD, Kinsella JP, Abman SH. The role of nitric oxide, endothelin, and prostaglandins in the transition of the pulmonary circulation. Clin Perinatol 1995;22:387-403.

25 Johnson GL, Cunningham MD, Desai NS, Cottrill CM, Noonan JA. Echocardiography in hypoxemic neonatal pulmonary disease. $\mathcal{F}$ Pediatr 1980;96:716-20.

26 Rozé JC, Storme L, Zupan V, Morville P, Dinh Xuan AT, Mercier JC. Echocardiographic investigation of inhaled nitric oxide in newborn babies with severe hypoxaemia. Lancet 1994;344:303-5. 